\title{
A Novel Approach in Estimation of the Soilcrete Column's Diameter and Optimization of the High Pressure Jet Grouting Using Adaptive Neuro Fuzzy Inference System (ANFIS)
}

\author{
Bijan Ehsanzadeh*, Kaveh Ahangari \\ Department of Mining Engineering, Faculty of Engineering, Tehran Science and Research Branch, Islamic Azad \\ University, Tehran, Iran \\ Email: ${ }^{*}$ bijan25318@yahoo.com
}

Received 11 June 2014; revised 10 July 2014; accepted 5 August 2014

Copyright (C) 2014 by authors and Scientific Research Publishing Inc.

This work is licensed under the Creative Commons Attribution International License (CC BY).

http://creativecommons.org/licenses/by/4.0/

(c) (i) Open Access

\section{Abstract}

For achieving optimized jet grout parameters and $\mathrm{W} / \mathrm{C}$ ratio it is concluded to set trial tests in constant local soil as the conclusion depends on local soil and presence of the extensive range of the effective parameters. Considering the benefits, due to abundance of the involved variables and the intrinsic geological complexity, this system follows a great expense in the trial and implementation phases. Utilizing the soft computing methods, this paper proposes a new approach to reduce or to eliminate the cost of the trial phase. Therefore, the Adaptive Neuro Fuzzy Inference System (ANFIS) was utilized to study the possibility of anticipating the diameter of the jet grout (Soilcrete) columns on the trial phase based on the Trial and Error procedure. Data were collected from several projects and formed three sets of data. Consequently, parameters were held constant (as input) and the diameters of the Soilcrete columns were recorded (as output). To increase the precision, aforementioned data sets were combined and ten different data sets were created and studied, with all the results being assessed in two different approaches. Accordingly, Gaussian Function results in a huge number of precise and acceptable outcomes among available functions. Based on the measurements, Gaussian Function achieves the values of the $R$ which are frequently more than 0.8 and lower values of the RMSE. Therefore, utilizing Gaussian Function, mainly a congruent relation between the $R$ and RMSE is experienced and it leads to close proximity of the actual and predicted values of the Soilcrete diameter.

\footnotetext{
${ }^{*}$ Corresponding author.
}

How to cite this paper: Ehsanzadeh, B. and Ahangari, K. (2014) A Novel Approach in Estimation of the Soilcrete Column's Diameter and Optimization of the High Pressure Jet Grouting Using Adaptive Neuro Fuzzy Inference System (ANFIS). Open Journal of Geology, 4, 386-398. http://dx.doi.org/10.4236/ojg.2014.48030 


\section{Keywords}

\section{ANFIS, Ground Improvement, Jet Grouting, Soft Computing, Soilcrete Column}

\section{Introduction}

Jet grouting is one of the best available methods of ground improvement. Jet grouting can provide the higheststrength treated ground in comparison with other methods of ground improvement. It can also be regarded as one of the most technically demanding ground improvement systems. In normal operation the drill string is advanced to the required depth and then high-pressure water or grout is introduced while withdrawing the rods [1]. One of the most important advantages of this method is its capability of treating different types of soils.

Nikbakhtan et al. [2] studied the jet grouting parameters of Shahriar dam in Iran on 2010. Based on their measurements, the diameter, Soilcrete Uniaxial Compression Strength (UCS), amount of the water, grout and air pressure and lifting and rotating speed in original site of jet grouting were 1.2 - $1.5 \mathrm{~m}, 2$ - $3 \mathrm{MPa}, 370$ - $390 \mathrm{bar}$, 10 - $15 \mathrm{bar}, 6$ - $8 \mathrm{bar}, 7-8 \mathrm{~cm} / \mathrm{min}$ and $7-8 \mathrm{~cm} / \mathrm{min}$, respectively. Also it could be seen that while the column diameter falls within the upper half of the range, some values of the compressive strength are close to the lower limit of the range. Nikbakhtan et al. [3] introduced new relations between Soilcrete diameter and its uniaxial compression strength with lifting and rotating speed, W/C ratio and grout pressure. According to the numerical outcomes obtained from their experiments the following individual results were achieved: 1) with increase in the grout pressure, UCS (MPa) of soil and diameter of the Soilcrete increase logarithmically; 2) with increase in W/C ratio, UCS (MPa) of soil and the diameter of the Soilcrete increase logarithmically; 3) with increase in lifting and rotation speed, UCS (MPa) of soil and diameter of the Soilcrete decrease logarithmically.

Tinoco et al. [4] utilized an advanced statistics analysis that is usually known as Data Mining (DM) techniques in their study to establish a new procedure to predict the Uniaxial Compressive strength (UCS) of the Soilcrete mixtures based on Support Vector Machines (SVM) algorithm. According to their investigations, such analysis identifies key variables in UCS prediction and measures its effects. Tinoco et al. [5] also trained multiple regressions, artificial neural networks, support vector machines and functional networks, in an individual study to predict the Young's modulus of Jet Grouting Laboratory Formulation (JGLF) over time. Moreover, a novel approach was proposed that was capable to predict JGLF stiffness based on its unconfined compressive strength and three other variables related to soil and mix properties through the application of DM techniques. In addition, Tinoco et al. [6] utilized (DM) techniques to predict deformability properties of (JGLF) over time. In their study, they compared three (DM) techniques in order to estimate the different modulus that can be defined in an unconfined compressed test of (JGLF) and identified key parameters in modulus estimation by performing a 1-D sensitivity analysis procedure. Above all, Tinoco et al. [7] studied the use of support vector machine (SVM) as a data mining algorithm which was able to explore high number of complex data for realizing the complex relationship between mechanical properties of jet grouting samples extracted from real jet grouting columns and its contributing factors. By performing a detailed sensitivity analysis, they discovered that the relation between the volumetric content of cement and mixture porosity and also the jet grouting system were the key variables in UCS prediction of jet grouting columns.

Wang et al. [8] introduced an approach of theoretical modelling of the mechanical phenomena induced by jet grouting and modeled the space between the injection nozzles and the intact soil based on the theory of turbulent kinematic flow. According to their studies, they established a relationship among jet parameters, column diameter and soil properties which were applicable for most soil types.

Kolovos et al. [9] investigated the combination of Soilcrete mixes with the addition of Metakaolin as a mineral admixture for soil improvements (especially in corrosive environments such as coastal regions) and discovered that the beneficial properties of metakaolin might be used in producing Soilcrete mixes with improved mechanical characteristics, which could be used as a temporary structural material.

The Adaptive Neuro Fuzzy Inference System (ANFIS) is a very powerful approach for modeling nonlinear and complex systems with less input and output training data, quicker learning and high precision. Its advantages are the expert knowledge of fuzzy logic and learning capability of neural networks [10]. To implement jet grouting system, at first a pilot (trial) phase should take place to study different variables of the local soil and jet 
grouting system. Mainly, this phase imposes a considerable expense to the project. Hence, to decrease or perhaps to eliminate this expense, ANFIS App was utilized for studying parameters of distinct projects and determining the diameter of Soilcrete column. In comparison with previous studies, since more data were utilized in this research, more precise and comprehensive outcomes would be predicted and therefore, the validity of this analysis increased.

This App could be adjusted to calculate with the exact value of tolerance for error in a calculation process. Therefore, it is possible to estimate the error value with zero tolerance. On the other hand, it can be easily trained with actual data from the previously done projects to find the best function that processes the test data and delivers the excellent congruency between the test data and actual data. Also, since fuzzy logic increases the robustness and accuracy of the results and still is not implemented in previous studies for anticipating the diameter of the Soilcrete columns, this paper represents a new approach that utilizes ANFIS App to predict the diameter of the Soilcrete column.

According to above explanations, one of the most important aims of this paper which is not considered in the previous investigations is the precise anticipation of the diameter of the Soilcrete columns and discovering a function that leads to the close proximity of the predicted and actual diameters of the Soilcrete. It should also be mentioned that all the previous studies were mostly focused on statistical procedures and results whereas this study used the actual numerical data of different projects and introduced a certain new numerical calculative method. Therefore, using this approach it is possible to anticipate the diameter of the Soilcrete, produce practical numerical outcomes and provide a prior attitude before the beginning of the jet grouting process. The $\mathrm{R}$ and RMSE are two basic criteria utilized to increase the precision of the process in this research. Furthermore, this study provides the exact breakdown of success estimation percentages for chosen functions.

\section{Materials and Methodology}

\subsection{Jet Grouting}

Jet grouting is mainly a complex procedure of grout injection inside soft soils that is divided into three methods of single, double and triple fluid systems. However, in early 1990s, a new method that used focused jets was invented to increase the diameter of Soilcrete columns. This procedure is called Super Jet grouting method [1]. The sequence of jet grouting method and different jet grouting systems are respectively shown in Figure 1 and Figure 2.

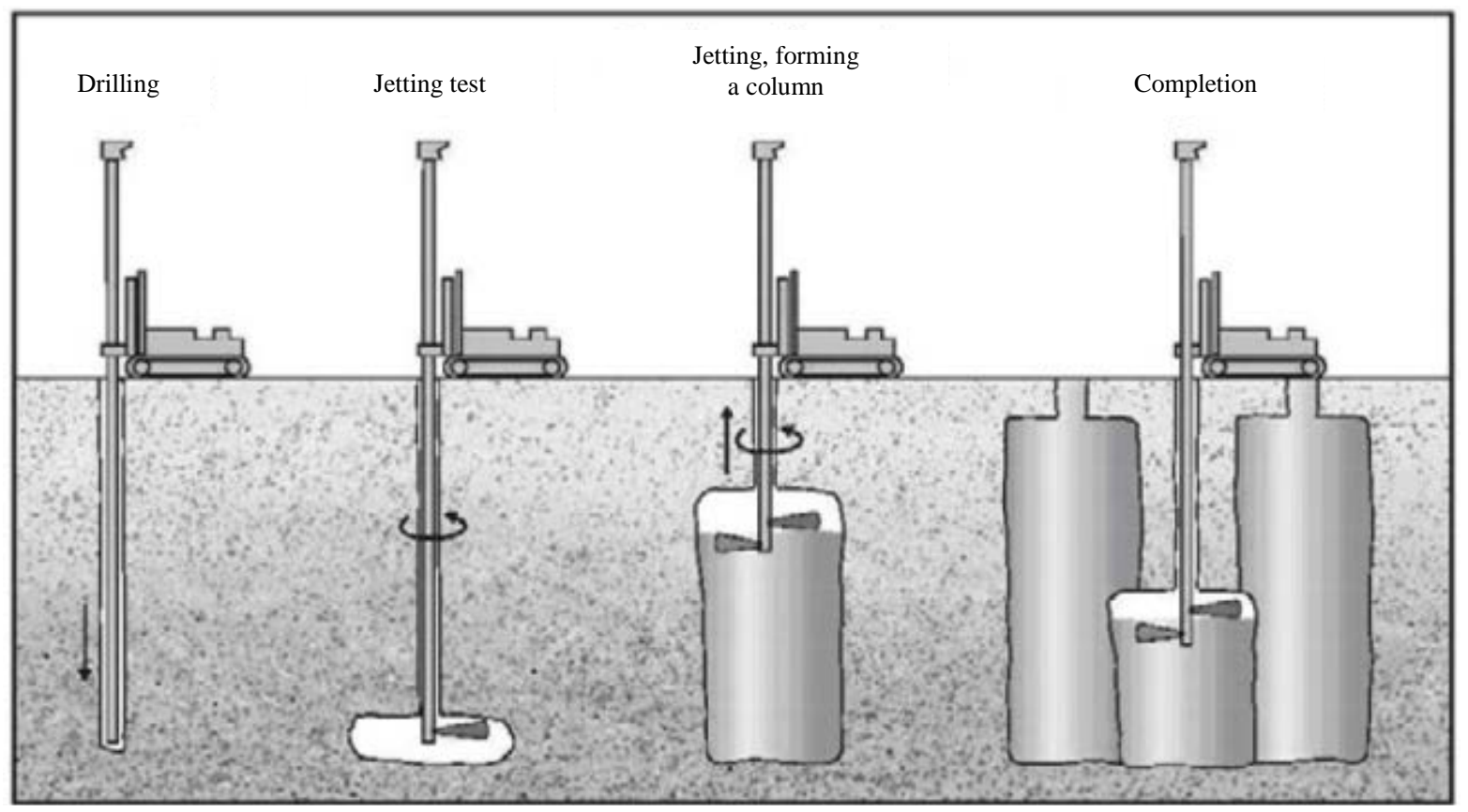

Figure 1. Sequence of jet grouting method [11]. 

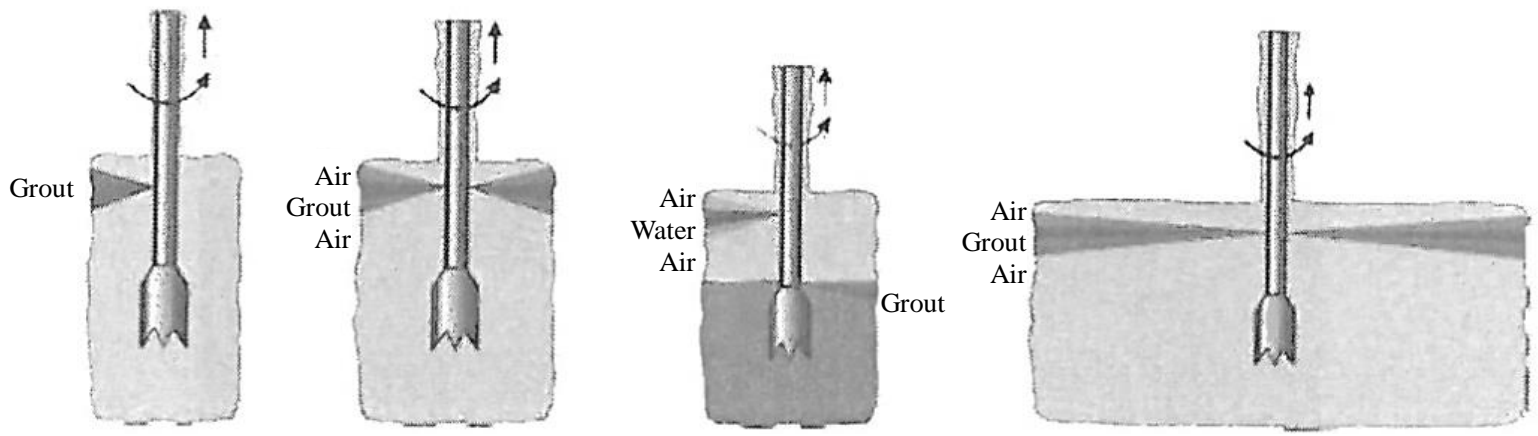

Figure 2. Single, double, triple and Super Jet grouting [1].

Basically, creating Soilcrete column, the high velocity jet erodes the underground soil and replaces some or all of them with grout material. Considering the equal condition for jet grouting and ground factors, Super Jet system is able to provide a considerably larger treatment of soil since it takes the advantage of the state-of-theart injecting system. As the equipment provides significantly higher flow rates at higher pressures, this method could improve volumes of soil 20 times as large as the previous conventional systems. This enabled jet grouting to obtain a column with a diameter in excess of 5 meters, or even 9 meters in softer ground [1]. However, triple fluid system still is more frequently used among all other systems.

Many individual factors affect the efficiency and productivity of the jet grouting. Therefore, this process requires meticulous considerations before designing and constructing the Soilcrete columns. Some of these affecting factors are: dynamic pressure, flow rate, compressed air, soil and etc. [1]. On the other hand, specifications of the Soilcrete columns achieved from the jet grouting procedures such as diameter and strength depend on jet grouting parameters such as grout pressure, lifting speed, rotating speed, number and diameter of nozzles, W/C rate and specification of local soil [12].

\subsection{Principles of the ANFIS}

Adaptive Neural Fuzzy Inference System (ANFIS) is fuzzy Sugeno model put in the framework to facilitate learning and adaptation procedure. The Sugeno fuzzy model was proposed by Takagi, Sugeno and Kang. Such network makes fuzzy logic more systematic and less relying on expert knowledge. The objective of this App is to adjust the parameters of a fuzzy system by applying a learning procedure using input-output training data. A combination technique of least square algorithm and back propagation are used for training fuzzy inference system [13]. Basic structure of this model, that has two inputs $x$ and $y$ and one output $f$ is shown in Figure 3.

A typical fuzzy rule in a Sugeno fuzzy model has the following pattern:

If $x$ is $A$ and $y$ is $B$ then $z=f(x, y)$. where $A$ and $B$ are fuzzy sets in the antecedent; $z=f(x, y)$ is a crisp function in the consequent [14].

\subsection{Data Collection and Preparation}

Data was collected from distinctive projects all around the world. Particularly, two of the main data sets were gathered from individual projects of Shahriar and Nian dams in Iran and the third data set was collected from other projects in United States, Canada and England [11] [15]-[19]. These three data sets were especially collected from projects that utilized triple fluid jet grouting system. It should be noted that, the specifications of jet grouting machine is not considered in this study.

Mainly, in these projects the soil had coarse grained alluvium accompanied by silt and clay layers and a continuous layer of clay. The trial test area had a superficial clay layer in depth of about $4.5 \mathrm{~m}$. Generally, the superficial layer in trial test area was divided in to 2 general groups of coarse grained and fine grained soils. Fine grain soils are mainly from clay with low plastic property or plastic sediment. In USCS (classification system) this soil is shown by CL/ML, CH/CL/MH/ML, ML symbols. Coarse grained soil consists of sand and gravel and is shown as GM in that classification system. Some physical and mechanical characteristics of these soils are: average liquid limit: 45, plasticity index: 20, water content: $38 \%$ and cohesion $40 \mathrm{kPa}$ [2].

In order to utilize ANFIS, the most effective involving variables were verified. Generally, based on the perspective of the American Society of Civil Engineers (ASCE), the effective parameters of jet grouting are: soil 


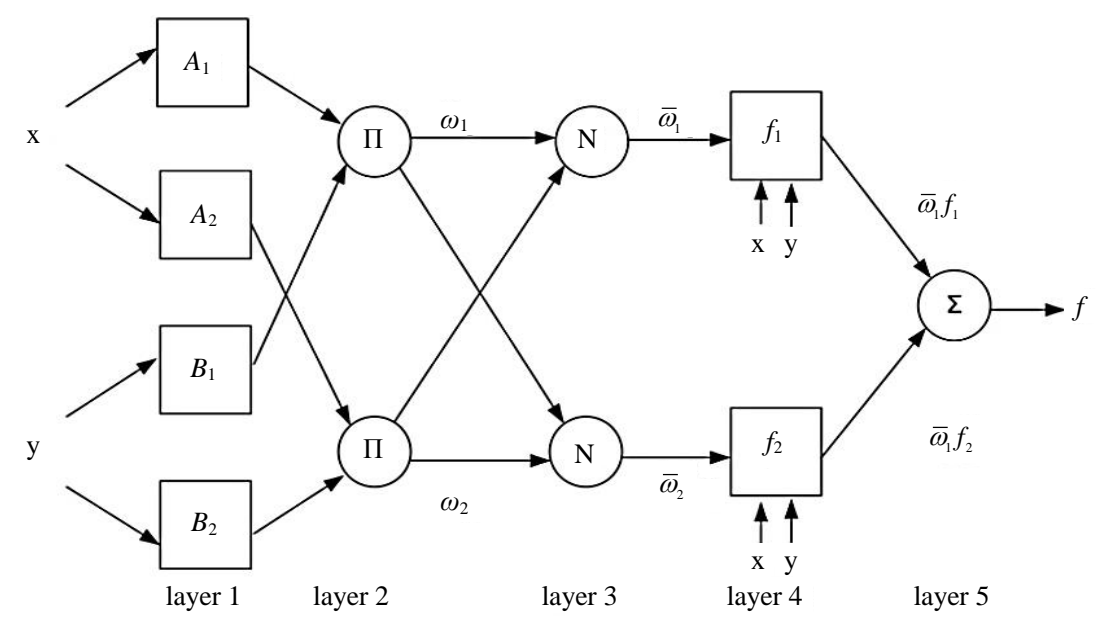

Figure 3. Architecture of ANFIS (two inputs-one output Sugeno fuzzy model with two rules) [13].

type, grout and soil mixing rate, output jet energy of the nozzle, grout flow, rod lifting velocity and rod rotation velocity [20]. Parameters that should be determined in single fluid system are: injecting pressure, number and dimensions of nozzles, water-cement ratio, rotation velocity, monitor set and injecting rod lifting rate. In double fluid system, in addition to aforementioned parameters of single fluid system, the air pressure and air flow parameters should be determined, but in triple fluid system beside these seven above mentioned parameters, the number of water nozzles and their corresponding dimensions and also the water pressure should be determined as well [17]. Apart from these previous studies, some questionnaires (see Table 1) were provided to inquire jet grouting experts of the Nian dam and Shahriar dam projects about their opinions on the effective parameters of jet grouting on the Soilcrete diameter. Finally, the parameters which are effective on the diameter of Soilcrete column in jet grouting method were selected according to above said investigations (see Table 2).

After selecting the effective parameters, the collected data formed three individual Excel sheets that were Nian dam, Shahriar dam and World data which were containing 10 of the aforementioned parameters and also the actual diameter of the Soilcrete column. Then, the data were analyzed in the Matlab software. Therefore, the data format had to be changed to one Excel sheet. Having changed the data format, two distinguishable groups were considered. The first group was composed of 10 individual input parameters such as lifting velocity $(\mathrm{cm} / \mathrm{sec})$, rotation velocity $(\mathrm{cm} / \mathrm{sec})$, water pressure $\left(\mathrm{kg} / \mathrm{cm}^{2}\right)$, air pressure $\left(\mathrm{kg} / \mathrm{cm}^{2}\right)$, grout pressure $\left(\mathrm{kg} / \mathrm{cm}^{2}\right)$, grout specific gravity $\left(\mathrm{N} / \mathrm{cm}^{3}\right)$, soil particle cohesion $\left(\mathrm{kg} / \mathrm{cm}^{2}\right)$, soil permeability coefficient $(\mathrm{cm} / \mathrm{sec})$, soil permittivity coefficient and inject ability ratio. The second group was composed of only one parameter which was the diameter of the Soilcrete column (cm) as an output. A sample of this data arrangement is exhibited on Table 2.

This resulted Excel sheet formed a matrix of $56 \times 11$ which consisted all gathered data. Afterwards, this final data sheet was combined in order to make 10 different Excel sheets with the same size. To do so, data in each Excel sheet was combined randomly to produce more precise and acceptable results.

\subsection{ANFIS Adjustments and Calculations}

The data, should be imported to Matlab software for analyzing. To do so, all of the final data should be divided into two groups of Train and Test data which are respectively consist of $75 \%$ and $25 \%$ of the available data on each Excel sheet. Therefore, in each Excel sheet, 49 cells were selected as train data and the rest 16 cells were considered as test data. This would result in more precise and suitable outcomes.

ANFIS should be prepared before commencing further analysis. Hence, as it is indicated in Figure 4 and Figure 5, these adjustments should be considered to achieve a rational precision:

a) The preparation method of the (Fuzzy Inference System) FIS Function should be adjusted on Grid partition method.

b) As it is shown in Figure 5, number of MFs should be considered as 2 on input section of the (Membership Functions) MFs adjustment menu. Moreover, in order to obtain comprehensive results, each of the MF types should be examined separately. In addition, MF type should be considered as constant on output section. It also 
Table 1. A sample of questionnaire table for determination of the effective parameters on the Soilcrete diameter.

\begin{tabular}{|c|c|c|c|c|c|c|}
\hline & & \multicolumn{5}{|c|}{ Level of importance for each parameter } \\
\hline & & $\begin{array}{c}\text { No } \\
\text { importance }\end{array}$ & $\begin{array}{c}\text { Low } \\
\text { importance }\end{array}$ & $\begin{array}{l}\text { Normal } \\
\text { importance }\end{array}$ & $\begin{array}{c}\text { High } \\
\text { importance }\end{array}$ & $\begin{array}{l}\text { Very high } \\
\text { importance }\end{array}$ \\
\hline \multirow{6}{*}{$\begin{array}{l}\text { Characteristics of } \\
\text { the injecting device }\end{array}$} & Water pressure & & & & & \\
\hline & Air pressure & & & & & \\
\hline & Grout pressure & & & & & \\
\hline & Lifting velocity of injecting rod & & & & & \\
\hline & Rotation velocity of injecting rod & & & & & \\
\hline & Grout specific gravity & & & & & \\
\hline \multirow{4}{*}{$\begin{array}{l}\text { Characteristics of } \\
\text { the injected ground }\end{array}$} & Soil particle cohesion & & & & & \\
\hline & Soil permeability coefficient & & & & & \\
\hline & Soil permittivity coefficient (Cg) & & & & & \\
\hline & Injectability ratio (GR) & & & & & \\
\hline
\end{tabular}

Table 2. Sample of arranged data containing effective parameters and the Soilcrete actual diameter.

\begin{tabular}{lcccc}
\hline \multicolumn{1}{c}{ Jet grouting input parameters } & Unit & Symbol & Data sample \#1 & Data sample \#2 \\
\hline Lifting velocity of injecting rod & $(\mathrm{cm} / \mathrm{sec})$ & $\mathrm{ls}$ & 0.108 & 0.083 \\
Rotation velocity of injecting rod & $(\mathrm{cm} / \mathrm{sec})$ & $\mathrm{rs}$ & 3.927 & 2.618 \\
Water pressure & $\left(\mathrm{kg} / \mathrm{cm}^{2}\right)$ & $\mathrm{Pw}$ & 350 & 400 \\
Air pressure & $\left(\mathrm{kg} / \mathrm{cm}^{2}\right)$ & $\mathrm{Pa}$ & 6.8 & 6.4 \\
Grout pressure & $\left(\mathrm{kg} / \mathrm{cm}^{2}\right)$ & Pg & 3 & 5 \\
Grout specific gravity & $\left(\mathrm{N} / \mathrm{cm}^{3}\right)$ & $\gamma \mathrm{g}$ & 0.0155 & 0.0155 \\
Soil particle cohesion & $\left(\mathrm{kg} / \mathrm{cm}^{2}\right)$ & $\mathrm{C}$ & 0.4 & 0.0135 \\
Soil permeability coefficient & $\left(\mathrm{cm} / \mathrm{sec}^{2}\right)$ & $\mathrm{K}$ & 0.0014 & $4.35374 \mathrm{E}-05$ \\
Soil permittivity coefficient & - & $\mathrm{Cg}$ & $4.35374 \mathrm{E}-05$ & 0.4 \\
Injectability ratio & - & $\mathrm{Gr}$ & 0.4 & 143 \\
Jet grouting output parameters & & & & 121 \\
Soilcrete column diameter & $(\mathrm{cm})$ & $\mathrm{D}$ & & 0.4 \\
\hline
\end{tabular}

should be mentioned that choosing linear method in this section would result in a time consuming analysis and production of inaccurate result.

c) FIS train method should be considered as Hybrid. Also, error tolerance should be considered zero and number of epochs should be set on 3.

d) On test FIS section, plot should bead justed to be checked against the checking data.

Having considered these adjustments, FIS was trained and then tested while all the errors were recorded. This process continued to reach the lowest possible testing error. Subsequently, expectation of the software for the test data was recorded. These 16 resulted data were the anticipation of the ANFIS for test data which are also known as anticipated diameters.

\section{Discussions}

Subsequent to achieving anticipated diameters for each function, they must be compared with the actual Soilcrete diameters to establish a new criterion. Therefore, using the R and RMSE criteria, both sets of the real and anticipated diameters were compared on an Excel sheet. Since 10 individual sets of data were considered for the analysis, results were recorded on tables of $10 \times 2$ which is shown on Table 3 .

Having created the aforementioned tables for the R and RMSE, the following statements were derived from the results:

1) According to the results that were derived from graphs (which are shown in Figure 6 and Table 3), Gaussian 


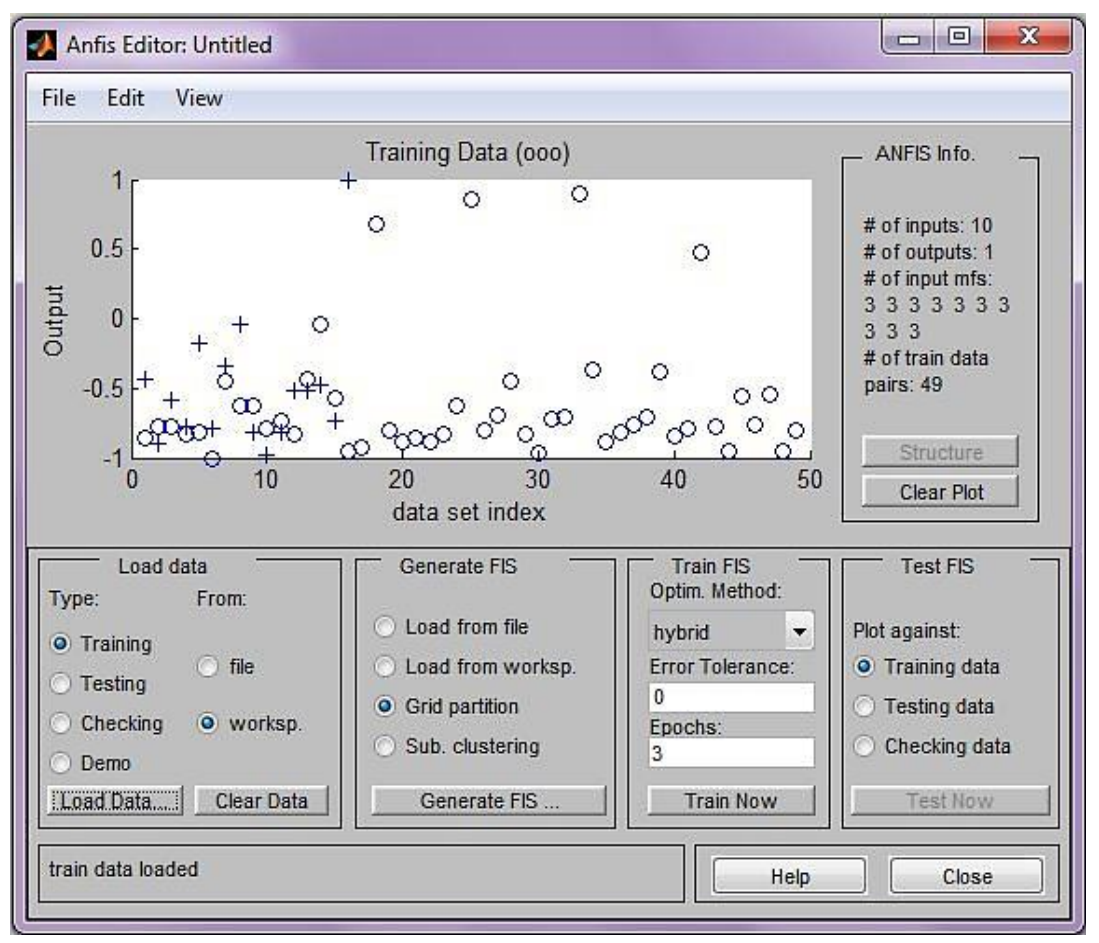

Figure 4. ANFIS interface with respective adjustments.

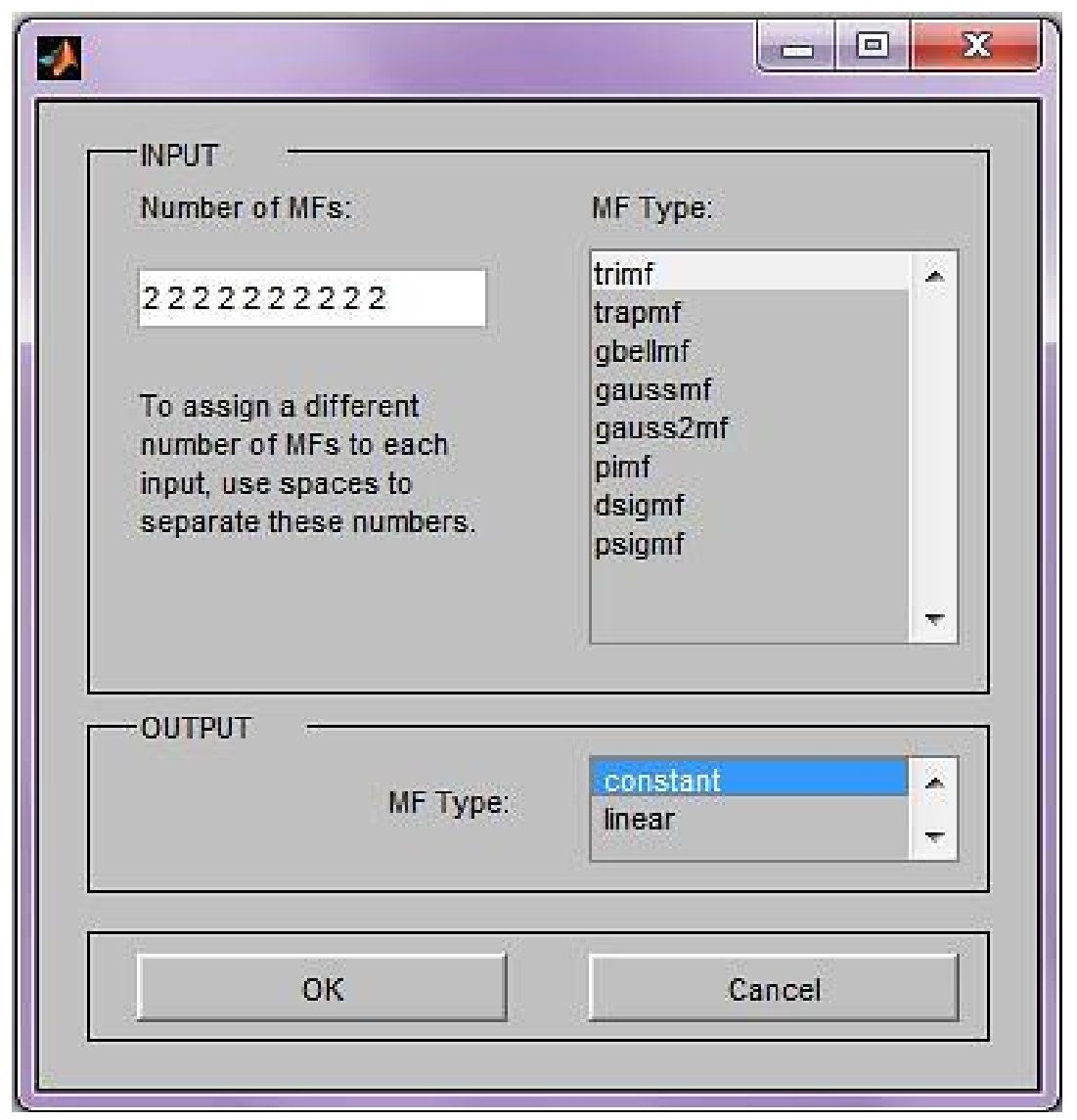

Figure 5. Input and output sections of the MFs adjustment menu. 
Table 3. Results acquired from Gaussian Function.

\begin{tabular}{ccc}
\hline & Gaussmf & \\
\hline Data set \# & $\mathrm{R}$ & RMSE \\
\hline 1 & 0.37167 & 1.379571693 \\
2 & 0.81257 & 6.81413933 \\
3 & 0.16053 & 51.27333072 \\
4 & 0.86829 & 28.37070291 \\
5 & 0.871 & 1.758375499 \\
6 & 0.5758 & 124.3354887 \\
7 & 0.68588 & 0.612820133 \\
8 & 0.87066 & 6.670367472 \\
9 & 0.6368 & 10.75031648 \\
\hline 10 & 0.83346 & 2.634421876 \\
\hline
\end{tabular}

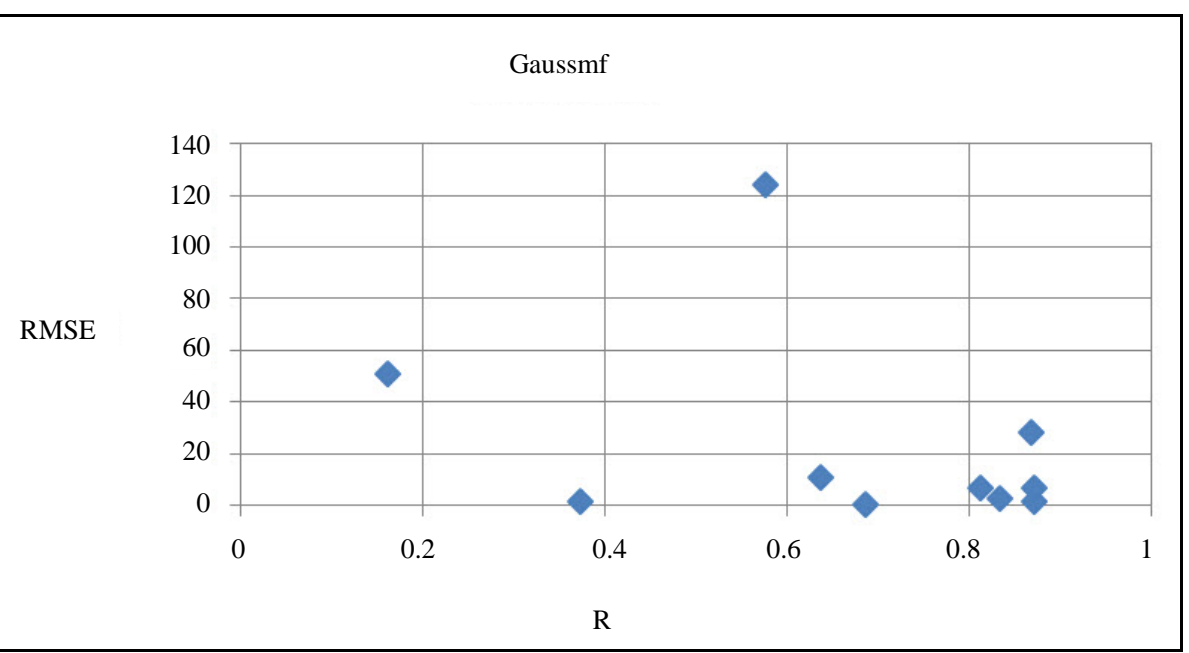

Figure 6. Gaussian Function graph of the R and RMSE criteria, accumulation of data in desirable area.

Functions, generally shows a vast amount of precision and a great congruity among all other available functions. However, measurements showed that the amount of the R for Gaussian Function differs from 0.160 to 0.871, but mostly they were in rational congruency with the RMSE and placed on the desirable area of the graph (see Figure 6). This area indicates the best results derived from the test which respectively includes the nodes with quantity of R between 0.8 and 1 and data with values of RMSE in minimum desirable amount. Therefore, the vast accumulation of nodes on this area depicts the extent of accuracy in Gaussian Function which leads to more desirable results.

2) According to the number of accumulated nodes on aforementioned desirable area, next two accurate functions which showed general precision were respectively Triangular and Trapezoid Functions. Their graphs are shown in Figure 7.

3) Pi Function showed the best proportion of the R and RMSE values on fifth data set (see Table 4). Although this function showed some valid results, but they were not quite abundant or in acceptable congruity.

4) Graphs related to other functions are also shown in Figure 8.

Therefore, in comparison with actual diameters of the Soilcrete, the results derived from the software showed that Gaussian Function leads to more precise outcomes and significant proximity of the predicted and actual 

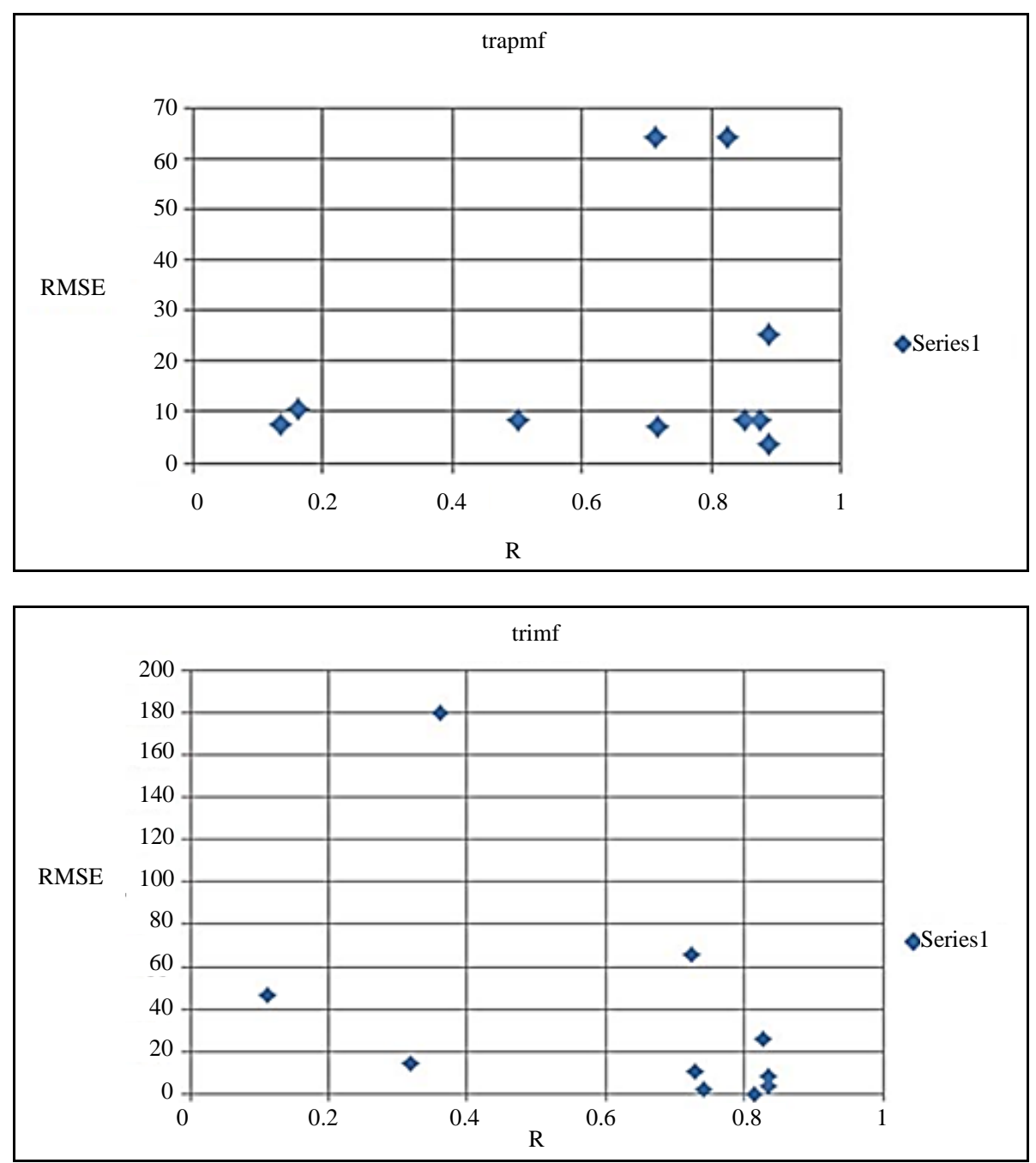

Figure 7. The triangular and trapezoid functions graphs (the R and RMSE criteria).

Table 4. Results acquired from Pi Function.

\begin{tabular}{ccc}
\hline & Pimf & \\
\hline Data set \# & $\mathrm{R}$ & RMSE \\
\hline 1 & 0.59266 & 3.5 \\
2 & 0.63022 & 64 \\
3 & 0.055412 & 1.173848789 \\
4 & 0.88083 & 25.25002179 \\
5 & 0.87988 & 1.276104528 \\
6 & 0.82468 & 64 \\
7 & 0.47961 & 6.731297313 \\
8 & 0.87143 & 8.499984257 \\
9 & 0.23477 & 10.75004125 \\
10 & 0.77432 & 6.430178002 \\
\hline
\end{tabular}



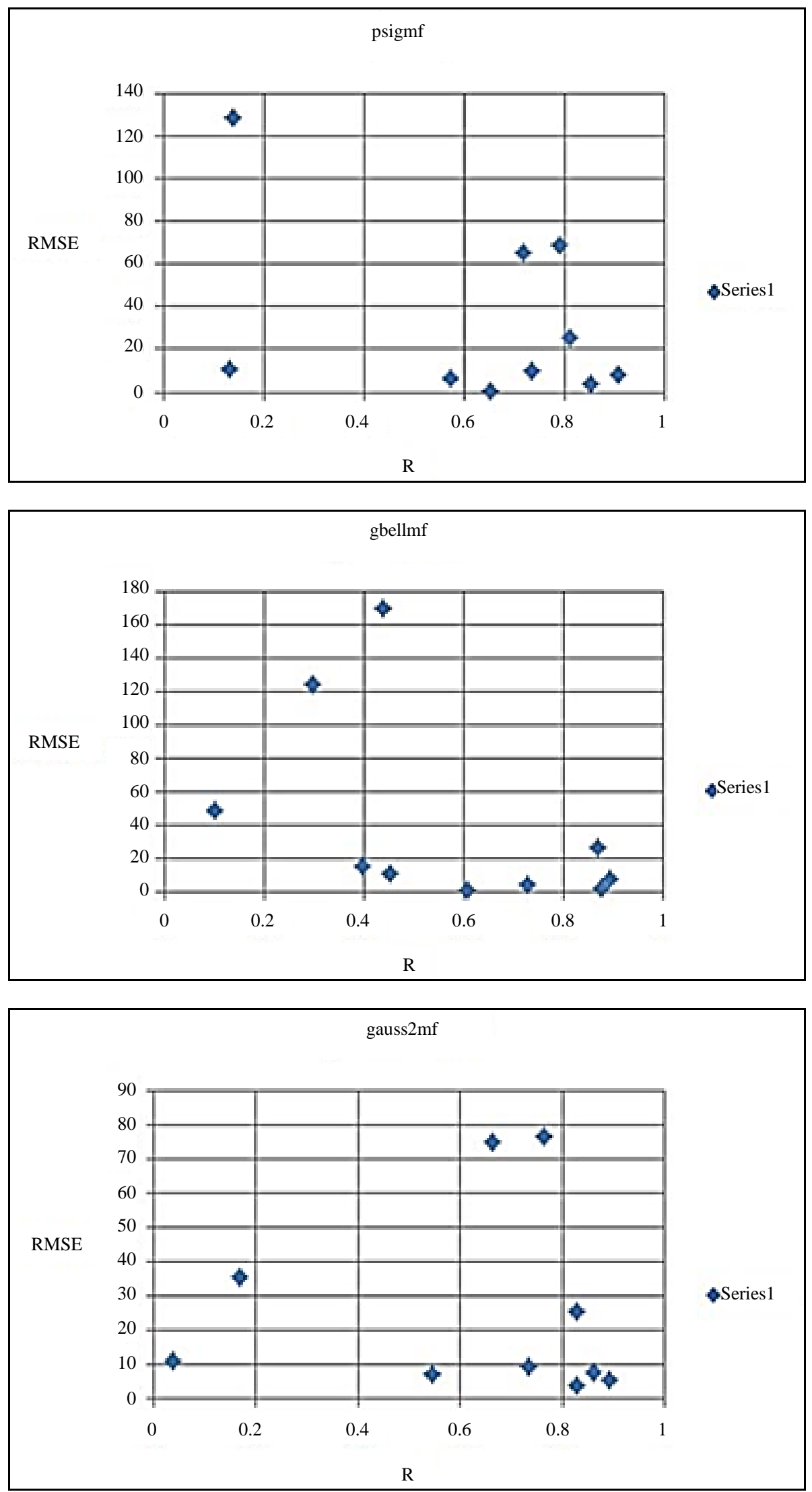

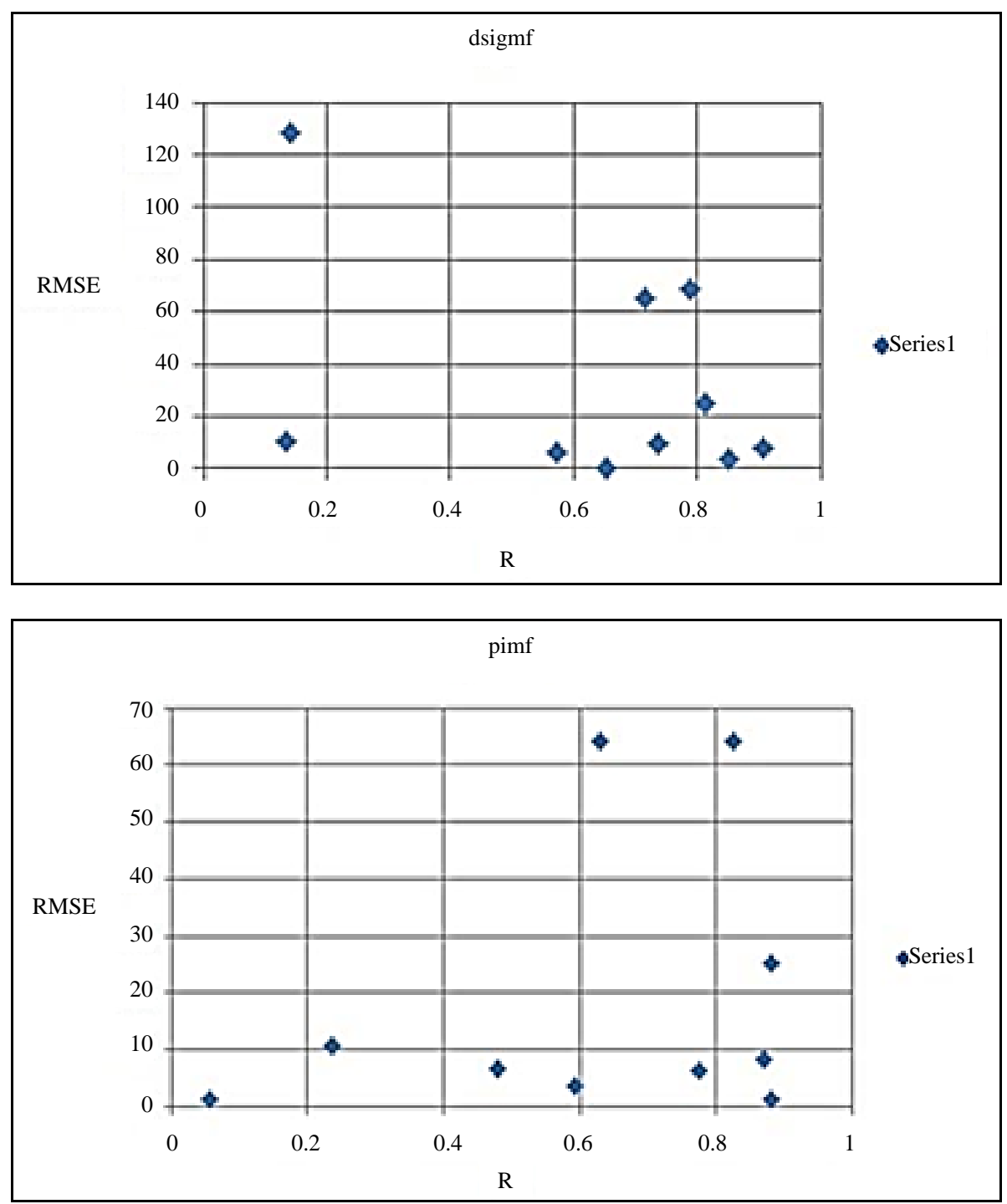

Figure 8. Other available functions’ results.

diameters of the Soilcrete columns. On the other hand, since ANFIS App is highly trainable and provides robust results, using the RMSE criterion, it has justified the results as well. Using the R criterion, it is also possible to increase the strength of outcomes in this study. Hence, according to the results and in comparison with neural networks, this App has the advantage of providing more accurate results that could be used to calculate the exact breakdown of success assessment percentages for chosen functions. In addition, it provides an occasion to anticipate the diameter of the Soilcrete column as an individual element only by using the characteristics of the ground and injecting device. On the other hand, this paper represents the use of a large number of data which were not experienced in any of the previous studies of jet grouting that increases the validity of this analysis.

\section{Conclusions}

Jet grouting is the most versatile method of grouting. Many different characteristics, parameters and criteria must be observed and adjusted meticulously to acquire the best possible results. Using fuzzy logic resulted in robust numerical outcomes and the ANFIS's predicted diameters were in close proximity to the actual Soilcrete diameters. Therefore, it is possible to provide a prior attitude in advance of the trial phase. Based on the outcomes it seems that the best possible procedure to gain a large number of rational and accurate results for the diameter of the Soilcrete column using this App is to utilize Gaussian Function. 
The best congruity between the R and RMSE as well as their quantities which were respectively propagated between $(0.160-0.871)$ and $(0.612-124.335)$ and also the frequency of desirable results, indicated Gaussian Function outcomes as the best and most acceptable results in this study. In addition, the accumulation of nodes on desirable area of the graph indicated that the Triangular and Trapezoid Functions respectively provided the second and third sets of accurate results. Based on these considerations, in the best possible condition, Gaussian Function indicated $40 \%$ of success ( 4 nodes out of 10 were in desirable area of the graph) in the modeling of the diameter of Soilcrete column while the Triangular and Trapezoid Functions respectively showed $30 \%$ and $0.5 \%$ of success. Also in their worst condition, Gaussian, Triangular and Trapezoid Functions respectively indicated $70 \%$ (7 nodes out of 10 were in desirable area of the graph), $60 \%$ and $30 \%$ of success.

On the other hand, only Pi Function showed the best result in both congruency and quantity perspectives. Since this result was only indicated for a single data set and the propagation and abundance of all other outcomes were extremely low, this function did not predict well and therefore it was not recommended to use this function.

In order to achieve better results in future, authors highly recommend the study of different specifications of jet grouting machines as well as all available injection systems.

\section{References}

[1] Burke, G. and Yoshida, H. (2013) Ground Improvement. Vol. 6: Jet Routing. 3rd Edition, CRC Press, New York, 207-258.

[2] Nikbakhtan, B., Ahangari, K. and Rahmani, N. (2010) Estimation of Jet Grouting Parameters in Shahriar Dam, Iran. Journal of Mining Science and Technology (China), 20, 472-477. http://dx.doi.org/10.1016/S1674-5264(09)60228-3

[3] Nikbakhtan, B. and Ahangari, K. (2010) Field Study of the Influence of Various Jet Grouting Parameters on Soilcrete Unconfined Compressive Strength and Its Diameter. International Journal of Rock Mechanics and Mining Sciences, 47, 685-689. http://dx.doi.org/10.1016/j.ijrmms.2010.03.004

[4] Tinoco, J., Gomes Correia, A. and Cortez, P. (2014) Support Vector Machines Applied to Uniaxial Compressive Strength Prediction of Jet Grouting Columns. Computers and Geotechnics, 55, 132-140.

http://www.sciencedirect.com/science/article/pii/S0266352X13001341 http://dx.doi.org/10.1016/j.compgeo.2013.08.010

[5] Tinoco, J., Gomes Correia, A. and Cortez, P. (2014) A Novel Approach to Predicting Young's Modulus of Jet Grouting Laboratory Formulations over Time Using Data Mining Techniques. Journal of Engineering Geology, 169, 50-60. http://dx.doi.org/10.1016/j.enggeo.2013.11.015

[6] Tinoco, J., Gomes Correia, A. and Cortez, P. (2011) Using Data Mining Techniques to Predict Deformability Properties of Jet Grouting Laboratory Formulations over Time. Progress in Artificial Intelligence, 7026, 491-505. http://dx.doi.org/10.1007/978-3-642-24769-9 36

[7] Tinoco, J., Gomes Correia, A. and Cortez, P. (2011) Support Vector Machines in Mechanical Properties Prediction of Jet Grouting Columns. http://hdl.handle.net/1822/15084

[8] Wang, Z.F., Shen, S.L. and Yang, J. (2012) Estimation of the Diameter of Jet-Grouted Column Based on Turbulent Kinematic Flow Theory. Proceeding of the 4th International Conference on Grouting and Deep Mixing, 2044-2051.

[9] Kolovos, K.G., Asteris, P.G., Cotsovos, D.M., Badogiannis, E. and Tsivilis, S. (2013) Mechanical Properties of Soilcrete Mixtures Modified with Metakaolin. Construction and Building Materials, 47, 1026-1036. http://dx.doi.org/10.1016/j.conbuildmat.2013.06.008

[10] Guney, K. and Sarikaya, N. (2006) Adaptive Neural Fuzzy Inference System for Computing the Physical Dimensions of Electrically Thin and Thick Rectangular Microstrip Antennas. International Journal of Infrared and Millimeter Waves, 7, 219-233.

[11] Poh, T.Y. and Wong, I.H. (2001) A Field Trial of Jet Grouting in Marine Clay. Canadian Geotechnical Journal, 38, 338-348. http://dx.doi.org/10.1139/cgj-38-2-338

[12] Nikbakhtan, B. and Osanloo, M. (2009) Effect of Grout Pressure and Grow Flow on Soil Physical and Mechanical Properties in Jet Grouting Operations. International Journal of Rock Mechanics and Mining Sciences, 46, 498-505. http://dx.doi.org/10.1016/j.ijrmms.2008.10.005

[13] Assaleh, K. (2007) Extraction of Fetal Electrocardiogram Using Adaptive Neuro-Fuzzy Inference System. IEEE Transactions on Biomedical Engineering, 54, 59-68. http://dx.doi.org/10.1109/TBME.2006.883728

[14] Jang, J.S.R. (1996) Input Selection for ANFIS Learning. Proceedings of the 5th IEEE International Conference on Fuzzy Systems, 2, 1493-1499. http://dx.doi.org/10.1109/FUZZY.1996.552396 
[15] Mahaab Ghods Corporation, Iran (2005) The Plan of Shahriar Dam in Azarbaijan-e-Sharghi. Documentary Report, 6.

[16] Khadamaat Mohandesi Mechanic Khak (SES) Corporation, Iran (2006) Trial Jet Grouting Report of Nian Dam.

[17] Xanthakos, P.P., Abramson, L.W. and Bruce, D.A. (1994) Ground Control and Improvement. Wiley Press, New York.

[18] Newman, R.L. and Essler, R.D. (1992) Jet Grouting to Enable Basement Construction in Difficult Ground Condition. Grouting in the Ground. Proceeding of Conference Organized by the Institution of Civil Engineering, London, 385401.

[19] Wong, H.I. and Poh, Y.T. (2000) Effects of Jet Grouting on Adjacent Ground and Structures. Journal of Geotechnical and Geoenvironmental Engineering, 126, 247-256. http://dx.doi.org/10.1061/(ASCE)1090-0241(2000)126:3(247)

[20] Covil, C.S. and Skinner, A.E. (1992) Jet Grouting, a Review of Some of the Operating Parameters That Form the Basis of the Jet Grouting Process. Grouting in the Ground. Proceeding of Conference Organized by the Institution of Civil Engineering, London, 605-628. 
Scientific Research Publishing (SCIRP) is one of the largest Open Access journal publishers. It is currently publishing more than 200 open access, online, peer-reviewed journals covering a wide range of academic disciplines. SCIRP serves the worldwide academic communities and contributes to the progress and application of science with its publication.

Other selected journals from SCIRP are listed as below. Submit your manuscript to us via either submit@scirp.org or Online Submission Portal.
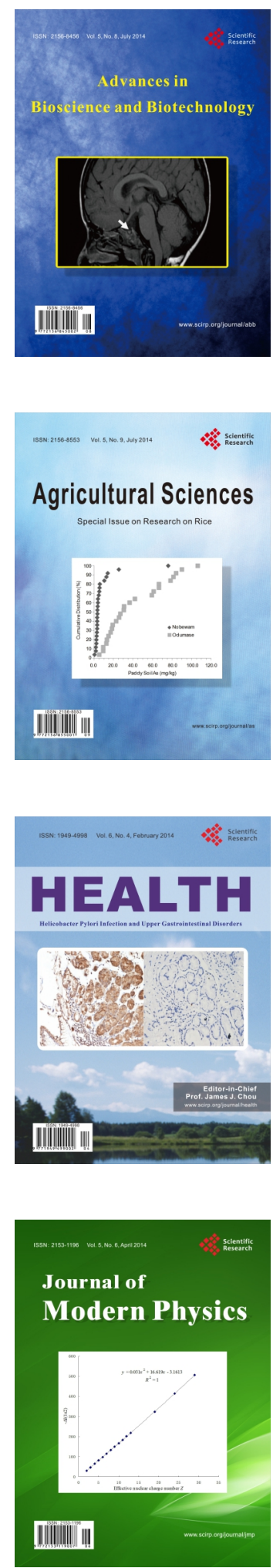
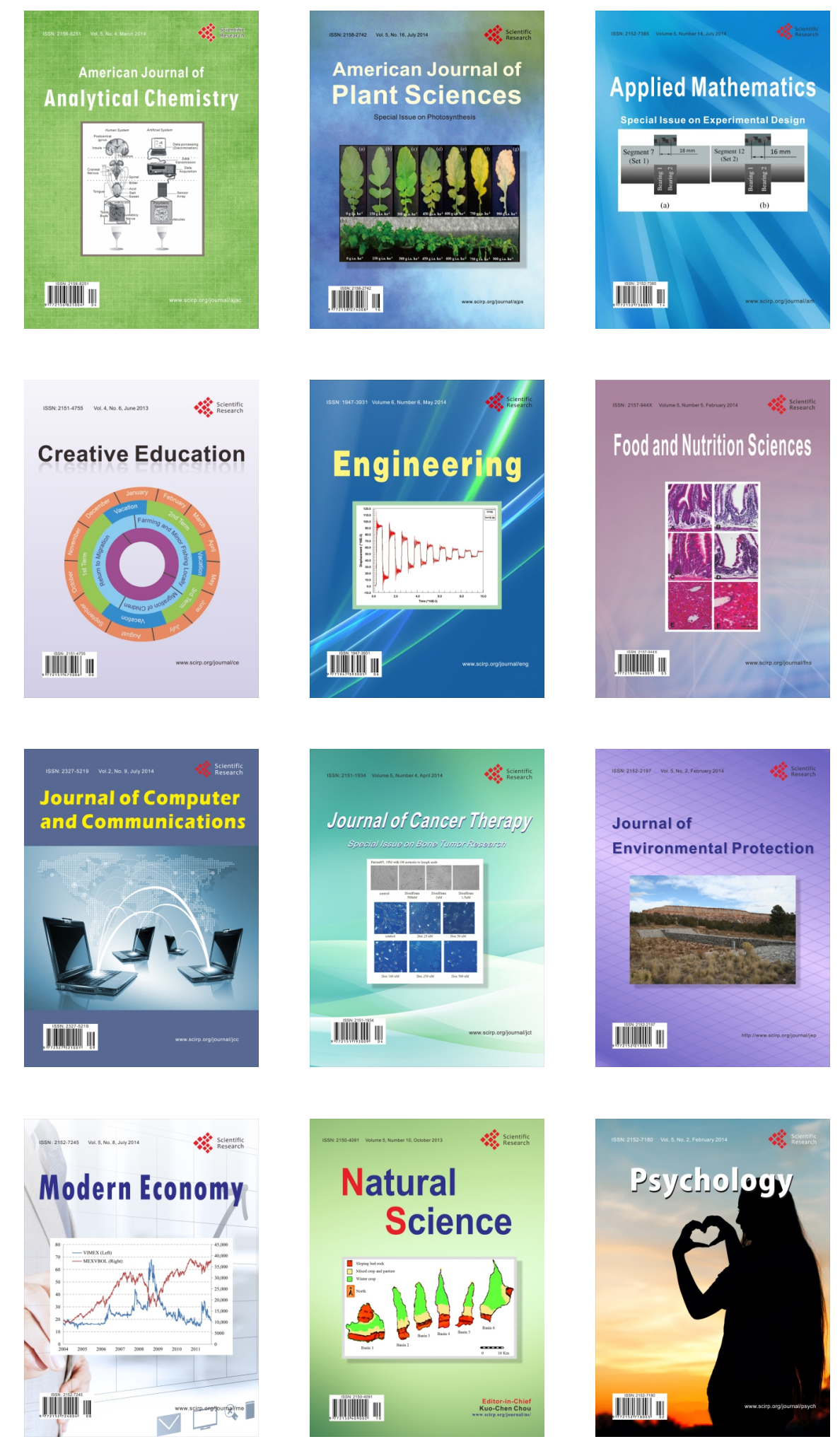